\title{
El trabajo público de los conceptos *
}

\author{
ANTONIO GÓmEz RAMOS
}

Universidad Carlos III de Madrid

RESUMEN. Este artículo trata de indagar en el sentido del aprendizaje de la historia, o de la elaboración del saber histórico, en la esfera política, y más precisamente, en la escena del espacio público de la modernidad. Se contrasta la noción de política en Hannah Arendt con la historia conceptual de Reinhardt Koselleck. Las definiciones arendtianas de política como libertad de palabra para la discusión plural y como recuerdo organizado se proyectan lingüísticamente en la propuesta de Koselleck de entender la política como una lucha por el significado de los conceptos sociopolíticos. El resultado es comprender la política como un «trabajo público de los conceptos», definición desde la cual se pueden aclarar algunas cuestiones sobre la historia y la memoria.

Palabras clave: política, historia, memoria, espacio público, historia de los conceptos, Arendt, Koselleck.

No es fácil definir en qué puede consistir realmente el saber histórico, si éste, por ejemplo, ha de considerarse algo más que el conocimiento discursivo acumulado en textos escritos acerca del tiempo pasado. En realidad, la propia noción de «saber histórico» parece tener una dimensión práctica y efectiva que reclama ir más allá de ese conocimiento discursivo. Las experiencias colectivas en el tiempo de las cosas humanas $-\mathrm{y}$ las experiencias individuales también, en la medida en que se hallan condicionadas, a veces determinadas, por esas experiencias colectivas - se precipitan en el contenido de un
ABstract. This paper deals with the question of how history can be learned, o some kind of hitorical wisdom can be attained, in the public realm of Modernity. Arendt's political theory is compared with Koselleck's history of concepts or Begriffsgeschichte. After working out, firstly, Arendt's notion of politics as fredom of word for plural discussion and as «organized remembrance», and secondly, the definition by Koselleck of politics as a «struggle for the meaning» of socio-political concepts, I come to the «public work on the concepts», a notion which ca shed light on some present issues on histoy and memory.

Key words: politics, history, memory, public realm, history of concepts, Begriffsgeschichte, Hannah Arendt, Koselleck.

saber cuyo sujeto no es sólo el estudioso de la historia, sino también quienes, como agentes o pacientes, están en ella. Este trabajo trata de abordar esa pregunta por el saber histórico desde una perspectiva política: no es la única, pero sí es decisiva en la medida en que toda política encierra necesariamente, y quizá predominantemente, un contenido histórico. La pregunta, desde esa perspectiva, se plantearía de este modo: cómo se elaboran las experiencias históricas en el espacio público. ¿De qué manera el espacio público, o la política, que por definición es el lugar del presente, de la actualidad, 
es también el lugar donde las vivencias colectivas pasadas - recientes o lejanas en el tiempo- se elaboran para convertirse en experiencias históricas? Se habla a veces de memoria colectiva, o de memoria social, también de memoria histórica, incluso de una sabiduría histórica colectiva, lo que conllevaría algún tipo de «aprendizaje de la historia»: la cuestión es de qué manera la elaboración de ese aprendizaje, de la experiencia histórica, por la que se sedimenta un saber histórico, tiene lugar en un espacio público que — como lugar común — marca y delimita el campo de la política.

Lo que aquí sugeriré es que esa elaboración de la experiencia histórica en el espacio público tiene lugar por un «trabajo público de los conceptos»: aunque la expresión tiene un sabor hegeliano, las líneas que propongo para concebir ese trabajo son la noción arendtiana de política y espacio público y la metodología de la historia conceptual de Koselleck, junto a algunas enseñanzas de Benjamin.

Es cierto que estos autores pertenecen a generaciones, estilos y filiaciones muy diferentes, y se desencuentran en muchísimos puntos, empezando por la noción de espacio público y la propia definición de la política. El estudio que hace Koselleck del espacio público ilustrado en Kritik und Krise es justo el reverso de lo que hizo Arendt o, inspirado en ella, Habermas: lo que para estos últimos es el origen de la política a plena luz es para aquél el mundo oscuro, o escondido, de la antipolítica. Pero Arendt y Koselleck coincidirían en criticar la deriva «moralista» que toma la política a partir de los salones del XVIII hasta llegar a la Revolución Francesa, y coinciden literalmente en su diagnóstico: los dos escriben, casi contemporáneamente, y desde lados reversos, casi literalmente lo mismo: que la filosofía de la historia de la modernidad ha tendido a anular o elimi- nar la posibilidad de la política. Así, mientras que Arendt se lamenta de que: «Cada vez que la Edad Moderna ha tenido razones para esperar una nueva filosofía política, se ha encontrado, en lugar de eso, con una filosofía de la historia» (1961, 298), Koselleck dedica todo el tercer capítulo de Kritik und Krise a argumentar que la filosofía de la historia de los Ilustrados descarga a éstos de toda responsabilidad política por tapar, e incluso reprimir (Verdrängen), la posibilidad de lo político.

Partiré de Arendt, y de un argumento que ella discute varias veces en favor de la memoria como sustancia de la política: o a favor de la convivencia política, directamente. Pericles, al final del primer año de la Guerra del Peloponeso, pronunció un discurso fúnebre por los atenienses caídos. En él argumentaba que si merece la pena vivir en una polis como Atenas, entendida como convivencia libre y organizada entre hombres diferentes, es porque sólo la polis ofrece una garantía a «quienes han obligado el mar y toda la tierra a ser accesibles a nuestra audacia», de que sus hazañas no caerán en el olvido. Atenas, esa comunidad política donde todos los ciudadanos son libres e iguales, y donde se da libremente el intercambio de ideas y modos diferentes de vida, hace innecesario a un Homero - cuyo canto sólo inmortalizaba a los héroes y a los dioses-. Gracias a que viven en la polis, los ciudadanos comunes recibirán el mismo trato que los héroes más grandes, pues tanto si caen en el combate como si sobreviven y realizan las mayores hazañas, permanecerán en el recuerdo de los contemporáneos y de las generaciones futuras, recibiendo de ellas el «elogio que no envejece». Los héroes reciben a veces grandiosas tumbas y sobreviven siempre en los cantos de la Odisea o la Ilíada; los que han vivido en la polis tendrán la tumba más insigne, que no es 
«aquella en la que yacen, sino aquella en la que su gloria sobrevive para siempre en el recuerdo, en cualquier tiempo que surja la ocasión para recordarlos tanto de palabra como de obra» ${ }^{1}$. La polis, tal como Pericles se la imaginaba, le da a los ciudadanos lo que la poesía sólo le ofrecía a los héroes, y ser ciudadano de la polis significa entrar en la posibilidad de la memoria.

De hecho, la política, según la desarrolla Arendt en La condición humana, es el invento al que recurrieron los griegos para superar la fragilidad inherente a las acciones humanas: éstas, como se sabe, son irreversibles, quedan huérfanas de su autor y resultan imprevisibles en sus consecuencias. Pero esa fluidez evanescente sólo se remedia por la solidez que les otorga la polis como recuerdo colectivo, como una «especie de recuerdo organizado» (organized remembrance): o dicho de otra manera: la política es siempre una construcción de la memoria y de la historia, y esa construcción no es un efecto secundario de la política, sino que forma parte de su definición más esencial.

Es importante depurar al máximo esta, que llamaré, «definición de Pericles», a fin de limpiarla de posibles interpretaciones más o menos fáciles que pueden parecer adheridas a ella. De hecho, a veces lo están, y puede que lo estén inevitablemente, pero entonces la alejan de lo que quiero mostrar a propósito del trabajo público de los conceptos.

1) En primer lugar, no se trata de un alegato comunitarista, ni siquiera nacionalista en sentido estrecho, étnico o religioso. El Pericles de Arendt no está apelando a una comunidad de tradición homogénea que recoge en su seno a todos sus miembros, vivos o muertos, y le da así sentido a la muerte y los sacrificios del pasado. De hecho, él insiste en la diferencia de estilos de vida que marca la libertad de la polis, En todo caso, el paralelo, más que el comunitarista, sería el de un nacionalismo moderno del estilo republicano francés y tal como lo ha estudiado Benedict Anderson, o el propio Koselleck en su politischen Totenkult: un culto secular que honra a los muertos. Pero para ellos, como para Pericles, y desde luego, para Arendt, se trata justamente de la falta de homogeneidad, de la no uniformidad entre los ciudadanos y, desde luego, la no uniformidad de los recuerdos. La definición arendtiana de política exige la pluralidad y la diversidad; Pericles hace hincapié en la convivencia entre sujetos diferentes y libres: no se trata, pues, de una homogeneidad de la memoria; ni, seguramente, tampoco comunidad de memoria. Esto es, aunque haya un ejercicio colectivo de memoria en el espacio público, no se está afirmando todavía sin más la existencia de una memoria colectiva sostenida en algún sujeto colectivo: algo contra lo que Koselleck precisamente se manifestó de modo repetido en sus últimos años, y en lo que basó sus críticas al reciente monumento al Holocausto de Berlín.

2) Tampoco se trata de las conmemoraciones más o menos rituales, y a menudo triunfalistas (y de orden militar, tanto en el discurso de Pericles como en las que conocemos de nuestro mundo) con las que las sociedades modernas honran a sus muertos. Posiblemente, estas conmemoraciones, que forman parte inevitable de todos los ejercicios de duelo y de recuerdo, tanto en la esfera individual como en la colectiva, son tan necesarias como banales. Pueden ser un lenitivo del dolor o pueden prestarse (de hecho es lo habitual) a los abusos más cínicos y patológicos por parte del poder de turno, como muy bien nos ha explicado 
Todorov (Todorov, 1996). Y desde luego, son parte de lo que Pericles y cualquier comunidad promete; también parte de lo que sus miembros le exigen. Pero la «definición de Pericles» ${ }^{2}$ no consiste en eso: la idea de que la política guarda la memoria de los suyos con elogio que no envejece $\mathrm{y}$ en tumbas insignes (que no es aquella material en la que yacen) produce, en efecto, las conmemoraciones, pero no se reduce a ellas, pues el proceso político de memoria y recuerdo remite a algo más esencial que la conmemoración.

3) Tampoco establece Pericles un imperativo ético de la memoria de los que tan en boga están hoy día. Con lo que he llamado "definición de Pericles», no está dicho nada sobre los usos y abusos de la memoria por parte de los agentes políticos en competencia, o del poder mismo. En realidad, si se pueden dar esos abusos como de hecho se dan a menudo- o se llega a plantear ese imperativo - como es el caso ahora de un modo crecientees porque no hay ciudad sin algún modo de memoria y porque, en cierto sentido, toda la actividad política conlleva un ejercicio colectivo de elaboración de la experiencia histórica pasada. La definición de Pericles no ordena recordar, sino que da por hecho que la polis «de por sí» recuerda, elabora el pasado en diversas versiones. De ahí los abusos y las patologías de la memoria.

Una vez que nos hemos deshecho de estas dos connotaciones, lo que nos queda del modelo de Pericles, por así decirlo, es una comunidad con una diversidad de memorias, a veces inconciliables entre sí, y además, con carácter reivindicativo. Lo que cada memoria plantea - al menos en la experiencia de nuestra época, de comienzos del siglo XXI- no es ya el re- cuerdo de «nuestras hazañas y nuestras audacias», no es una historia de héroes, sino una reivindicación del daño pasado: nuestra experiencia es que son las víctimas, quienes han sufrido daño, los que reivindican su recuerdo, y exigen de la sociedad -y también del cuerpo político- que haga justicia a ese recuerdo: las de las dictaduras (Argentina, España), las de la Shoa, las del stalinismo, Sudáfrica, etc. Una memoria, pues, dividida y fragmentada.

En cierto modo, lo que la «definición de Pericles» dice que hace la política democrática es afrontar dos tareas imposibles y muy benjaminianas.

1) Por un lado, pareciera que la polis se propone cumplir el deseo del ángel de la historia de «despertar a los muertos y recomponer lo despedazado», de hacer justicia a las víctimas (Benjamin, 1940).

2) Por otro, además, lo que la polis se propone es un trabajo de transmisión de la experiencia a través de las generaciones. Esa transmisión que, para el Benjamin del ensayo sobre Experiencia y pobreza se realizaba sin fricciones en el mundo premoderno, y que habría quedado irremediablemente rota a raíz de la Primera Guerra Mundial que había dejado a los hombres - tanto a los que volvían del frente como a sus hijos - más pobres, y huérfanos de experiencia.

De cumplir las dos cosas, la política podría ser, caso de realizarse de verdad, el momento de la redención y del tiempo - ahora al que se refiere Benjamin. De hecho, hay caracterizaciones de la política de Hannah Arendt- en cuanto espontaneidad e irrupción en el tiempo cotidiano de la palabra política humana - que apuntan en esta dirección-. Pero sabemos también que, igual que la redención no ha llegado — ni va a llegar-, la políti- 
ca no resuelve del todo esas tareas, sino que se ve sobrepasada por ellas, que son las que le dan lugar. Propiamente, no está vinculada al huracán progreso, sino al desfase y desacoplamiento de los tiempos que mueve la historia (y que es probablemente otro modo de llamar al progreso); es moderna porque no resuelve la ruptura de la experiencia sino que nace directamente de ella. La ruptura de los tiempos, la pérdida del vínculo con la experiencia pasada es precisamente la condición de la política.

Este punto es importante porque, entonces, la «definición de Pericles» presupone una experiencia de ruptura, de pérdida a la que la polis viene a ser respuesta, y donde encuentra su sentido: la marcha de los tiempos descoloca a los hombres, que buscan en la acción - o en la pasividad - política un modo de recolocarse. De hecho aquí vuelven a coincidir Koselleck y Arendt en diagnosticar la modernidad como una experiencia de pérdida y ruptura. Koselleck la define como la aceleración creciente de la historia que, aunque a veces reciba el nombre de progreso para suavizarla, no es sino la desconexión creciente, aceleradamente creciente, entre el campo de experiencias (Erfahrungsraum) y el horizonte de expectativas (Erwartungshorizon). Arendt la describe como la brecha entre el pasado y el futuro, y recurre a la cita de Tocqueville: «Como el pasado ya no nos ilumina, el presente camina entre tinieblas». En ambos casos, el presente moderno como perplejidad y desconcierto. En ambos casos, la denuncia del más exitoso - retóricamente - intento de respuesta a esa perplejidad, a saber, la filosofía clásica de la historia, que tendía a articular la brecha, o la desconexión, por medio de un programa teleológico. Otra segunda vía - aquella que la filosofía clásica de la historia ocultaba, o tapaba, que vuelve con fuerza ahora cuando la esa filosofía de la historia ha llegado a su final — es la política, entendida, al modo de Pericles, como transmisión de la experiencia, asunción del pasado hacia el futuro, justo cuando las vías de transmisión se han roto, cuando la experiencia es más bien la ruptura de toda experiencia — de la que son expresión las diversas catástrofes del siglo XX, o las catástrofes de las que sólo a posteriori nos vamos haciendo conscientes (colonialismo, esclavitud, discriminación de género, etc.). Una tercera vía más, cercana a Koselleck, pasaría por un conocimiento histórico que reconociese las estructuras más duraderas —aunque nunca permanentes_-, de la historia, o de variación más lenta, y reconociese la dinámica de su variación. Tales estructuras son lingüísticas, y de ellas se ocupa la historia conceptual. Lo que quiero mostrar aquí es hasta qué punto la segunda vía, la de la política de Arendt-Pericles, necesita el complemento de la tercera.

En todo caso, la política no tratará de sanar, restaurar la continuidad (ésa era la aspiración romántica), sino reconocerá de partida cuáles son sus condiciones: sólo en virtud de la desconexión entre horizonte y expectativa, del desacoplamiento de los tiempos, de la brecha entre el pasado y el futuro, de la desorientación que de ahí resulta, y que socialmente se plasma en la diversidad de los agentes y los intereses, llega a darse la política. La democracia ateniense, el liberalismo bien entendido y todas las promesas y posibilidades de transformación revolucionaria nacen siempre en momentos de ruptura y de pérdida, y para asumirla. Siempre hay un cierto trabajo de duelo en el proceso de la política.

Arendt propone una segunda definición de la política, que insiste más en la diversidad y la pluralidad que en el problema del tiempo. La política, dice, es la «libertad de palabra para la discusión entre ciudadanos iguales y plurales» $(1995$, 
5). La política - cuando se da - es la interacción ${ }^{3}$ entre individuos que actúan espontánea y libremente - liberados de las ataduras inmediatas del trabajo y de lo privado - en un espacio público, y por esa interacción lo constituyen. Además, el juego de esa libertad de palabra en el espacio público tiene lugar, como Arendt trató de estudiar intensamente durante sus últimos años, por medio de la facultad de juzgar: la capacidad para pensarse en el lugar de los otros, esa destreza, en principio estética, que exige la pluralidad de los seres humanos, y que, porque no opera según el juicio determinante, puede hacerse cargo de la contingencia y de la singularidad de las acciones humanas.

A pesar de su aparentes diferencias, hay un hilo oculto entre la primera definición de polis a propósito de Pericles — recuerdo organizado - y esta última que hemos dado aquí — libertad de palabra para la discusión entre ciudadanos libres e iguales-. Creo que Arendt es consciente de ese hilo, aunque no lo hace explícito del todo, o al menos, no extrae plenamente sus consecuencias. Es éste: la palabra de la acción humana que constituye el espacio público de la política, es - con toda su espontaneidad, con toda la espontaneidad con que el actor la introduce en el debate político - una palabra cargada de historia, lleva en su seno - actuando semánticamente con ellatodo un sedimento (o un lastre) de experiencias colectivas y personales, unas veces más conscientes que otras. Y es precisamente esa carga histórica de la palabra la que le otorga todo su peso y efectividad en el espacio público.

Sin embargo, Arendt - que, a pesar de su ascendencia heideggeriana, no tematizó en su obra el giro lingüístico del siglo XX - no ahondó en esa carga histórica de las palabras, ni siquiera cuando estudió los momentos revolucionarios, en los que la densidad semántica de los con- ceptos políticos más se trastocaba y trastocaba el escenario. A Arendt no le faltaba sensibilidad lingüística, en absoluto, y cualquier lector suyo aprecia sus saltos filológicos hacia atrás en el tiempo para precisar magistralmente el significado griego o latino de un concepto sociopolítico. Pero, si se entretenía en la historia de las palabras, solía ser sólo para dar con su origen prístino; y aquí era Heidegger quien la determinaba. En cambio, por otro lado, sí era consciente de la complejidad con que la carga histórica forma parte de la actividad política. Quizá uno de los temas más delicados de su pensamiento sea el de cómo la facultad que permite intervenir en la política y la constituye es la misma facultad que nos permite tener un sentido histórico y articular el pasado con el presente. Se trata de la Urteilskraft kantiana.

Kant había mostrado, según Arendt, que la capacidad para ascender desde lo particular (y por lo tanto, contingente) hasta lo universal (y eso es lo que hace el juicio reflexionante) — capacidad que actúa tanto cuando construimos conceptos (en la primera Crítica) como en la apreciación estética (en la tercera) - requiere de la pluralidad, de la existencia de los otros; de hecho, tener juicio es poder abstraer de la propia subjetividad particular y «ser capaz de pensarse en el lugar de otro», es tener una «mentalidad ampliada - erweiterte Denkungsart_-: dar por hecho de veras que hay otro. Por eso la facultad de juzgar es la facultad política por antonomasia y la Crítica del Juicio es una obra política (Arendt, 1982).

Pero, a la vez, esa capacidad para producir lo universal a partir de lo particular es lo que puede convertir a cada actor de la política en un Weltbetrachter, en un observador distanciado (y a veces entusiasmado) y cosmopolita que puede insertar el caos de acontecimientos contingentes e inconexos - la «historia de rui- 
do y furia contada por un imbécil» (Macbeth), o el «tapiz humano entretejido con hilos de locura, vanidad infantil y maldad y afán destructivo» (Kant) — en una historia que les da significado (por ejemplo, para Kant, la historia del progreso). La misma facultad que le permite al hombre discutir con los otros es la que le permite contar historias. Por eso, las dos definiciones de Arendt son consistentes. La Urteilskraft le permite al que la tiene, no sólo interactuar con sus contemporáneos — ser un zoon politikon-, sino hacer juicios históricos y situarse en el tiempo — ser una conciencia histórica o alguien con sensibilidad para los cambios históricos y para la elaboración de la experiencia pasada. «Dentro de cada actor político hay un espectador que juzga históricamente» $(1982,8)$. El juicio, pues, mira hacia atrás, hacia el pasado, y a la vez, hacia los lados, a los otros con los que se interactúa, a la situación presente que se evalúa y en la que se toman decisiones o se inician cursos de acción.

La propuesta de Arendt, con todo lo sugerente que es, permanece envuelta en no pocas aporías: nunca queda claro si la sede del juicio es el actor o el espectador; cuál es la posibilidad de la institucionalización de la política, dónde se ejerce el juicio realmente, etc. Para nuestros efectos, podríamos formularlo así: por mucho que haya un «historiador dentro de cada actor»: ¿cómo coinciden el espectador kantiano de la historia, el que se entusiasma ante el sublime espectáculo de la revolución ajena, con el ciudadano que, en la polis que Pericles define, participa en el proceso de elaboración y transmisión de la experiencia pasada? ¿Cómo se puede a la vez llevar el pasado a cuestas y estar discutiendo en el presente sobre las iniciativas del futuro?

Aquí es donde la propuesta de Koselleck de una historia conceptual (Begriffsgeschichte) puede resultar fecunda; y ello, en un doble sentido. No sólo para desarrollar nuestra pregunta por el lugar y el desarrollo de la elaboración de la experiencia histórica; sino, también, a la inversa, para extraer de Koselleck potencialidades críticas que en él no están desarrolladas, o lo están muy discretamente, y que sus lectores echan a menudo en falta ${ }^{4}$. Potencialidades que tiene que ver con lo que podríamos llamar un «uso público de la historia», o de la «razón histórica» en el que la propia actividad de la política procesara y elaborara de manera responsable las experiencias del pasado.

Propiamente, la Begriffsgeschichte es una «estrategia de análisis del discurso sociopolítico» que pretende corregir las limitaciones de muchos enfoques historiográficos de las ideas políticas. Como es sabido, las correcciones se dirigen en dos frentes: por un lado, frente a la historia de las ideas, o la historia intelectual, que estudia las ideas como entidades constantes e invariables a través de la historia, como si los conceptos sociopolíticos nunca hubieran cambiado a lo largo del tiempo y pudieran ser fijados por ello en un diccionario, cuando no en una estructura ideológica firme; por otro lado, frente la actitud complementaria de esa historia de las ideas, esto es, a la aplicación anacrónica de los conceptos del presente al pasado — como cuando se llevan términos como clase, Estado, autonomía, entendidos como se entienden hoy, al estudio de la Edad Media-, muy común entre historiadores; era un modo de proceder muy propio de los historiadores hasta la llegada de la historia conceptual. El proyecto de Koselleck trata de estudiar diacrónicamente los conceptos político-sociales en su evolución semántica - esto es, los conceptos pueden ir variando su significado a través del tiempo, tienen también una historia- $y$, a la vez que en el complejo sincrónico constituido por su interrelación presente — cada concep- 
to, por antiguo y rancio que sea, tiene su significado en cada momento histórico determinado por el contexto sociopolítico y por el entramado de los otros conceptos reconocidos en este momento-. Se trata, entonces, de estudiar los conceptos sociopolíticos adecuadamente a su momento presente. Ello supone, por un lado, reconocer que estos están sometidos a una evolución semántica que, por el rigor del historiador, es obligado respetar y conocer. Pero también supone admitir que los conceptos no sólo son indicadores de las representaciones que tengan los agentes políticos en un momento determinado, sino también factores, en la medida en que, en virtud de sus particulares representaciones, los agentes guiarán su acción. Esto es, como los conceptos se convierten, para los agentes en «esquemas de orientación y de acción para la praxis y la teoría» —esto es, los conceptos, o el significado que los agentes atribuyen a los conceptos es lo que determina y marca los límites posibles de la acción política, resulta que los conceptos tienen un valor constituyente de la sociedad en la que se los utiliza. En cierto modo - aquí Skinner es bastante más explícito que Koselleck-, los conceptos se aplican en actos de habla con los que la sociedad se constituye lingüísticamente. Los conceptos se usan performativamente. Al historiador, conocer el significado de los conceptos en un momento determinado le permite conocer la sociedad política en ese momento; pero, a la vez, conocer la evolución semántica de los conceptos - en general, más lenta que la de los acontecimientos - le permite comprender la lucha político-social por la que la sociedad va modificándose.

Lo decisivo aquí es que, de este modo, en la medida en que los conceptos, tal como los entienden y usan los agentes, recogen toda una historia semántica y orientan también significados futuros, a la vez determinándolos y limitándolos, la política queda entendida como un «proceso constante de temporalización de la experiencia» (Chignola, 2006). De hecho, estudiar la historia de los conceptos no significa sin más reconstruir históricamente un léxico político (como pudiera serlo, por ejemplo, los Geschichtliche Grundbegriffe), recomponiéndolo más allá de sus crisis, sino asumir verdaderamente que la transformación y la crisis son los elementos que revelan la cualidad específica de la política.

Como es sabido, Koselleck y su equipo aplicaron sistemáticamente este programa al estudio del llamado Sattelzeit: desde mediados del siglo XVIII, justo cuando nace la historia, «tiene lugar un profundo cambio semántico en todos los topoi clásicos, de modo que palabras muy antiguas del vocabulario político y social adquieren nuevos significados.» (Koselleck, 1973, 14). Los conceptos, además, tienen en ese período un rostro jánico, en tanto que a la vez recogen experiencias pasadas y proponen expectativas de cambio, expectativas que, a su vez, dan lugar a nuevos esquemas conceptuales que marcan el límite y las posibilidades reales de cambio. Así, la distinción, que Diderot consigue poner en circulación, entre citoyen y bourgeois contribuyó decisivamente a determinar la autocomprensión política, y el propio curso de la política, en Francia; y la unificación de los dos términos en el Bürger alemán era un indicador, y en parte también un factor, de los límites internos de la política alemana frente a la francesa. (Koselleck, 2006, 42 s.)

Durante el Sattelszeit, entonces, lo que tiene lugar es un cambio en la experiencia histórica: el agujero negro de las guerras de religión y el absolutismo que le sigue provoca una catástrofe del léxico político previo y obliga a una reordenación conceptual. Los conceptos tienen que realizar un trabajo de reinscribir y reins- 
cribirse en una realidad efectiva cambiante. Es un trabajo arduo, que da la dimensión hegeliana del saber histórico de la política que tratamos de dibujar ${ }^{5}$ : su continuo desfase respecto a ella - lo que Hegel hubiera llamado, justamente, la experiencia de lo negativo ${ }^{6}$ - les hace a los conceptos recoger la experiencia con la suficiente imprecisión como para, a la vez, modificarla y modelarla, introduciendo en ella expectativas que trazan el horizonte y los límites de toda experiencia posible. Es justo a ese trabajo conceptual al que tiene que atender el historiador, trabajando a la vez en el campo de las palabras y en el de la realidad política que aquéllas expresan.

Hegel decía que ese trabajo del concepto - que para él era la historia misma- requiere de una inmensa paciencia en el trabajo del espíritu con lo negativo. Un lector muy inmediato de Hegel diría: como si hubiera una resistencia igualmente inmensa de la realidad a dejarse atrapar, a coincidir con el concepto, de modo que éste no pudiera abrazarla del todo. La perspectiva de la historia conceptual nos enseña que esa resistencia no es tal, no es la de un objeto externo, sino que es la propia fragilidad interna, el carácter quebradizo de los conceptos mismos, cuya fractura interior es a la vez motor y resultado de ese trabajo, y dibuja las líneas de la evolución sociopolítica de la modernidad. El historiador atiende, en efecto, al trabajo del concepto, pero no a sus choques con la realidad - como si ambos se dieran por separado_- sino a su dispersión en las realidades de quienes los usan. Es atendiendo a esto como la «historia conceptual» termina por encontrarse - como dos piezas de un puzlecon la definición arendtiana de política que he expuesto. Y la historia conceptual resulta ser no sólo asunto de historiadores, sino también del observador político $\mathrm{y}$, desde luego, del observador político que hay dentro de cada actor.
Pues si los conceptos están internamente fracturados, es porque la lucha sociopolítica de la Edad Contemporánea es, sobre todo, una «lucha por el significado» de un concepto, una lucha por delimitar y modelar ese significado con más fuerza que el bando contrario. Algún comentarista ha llegado a reformular esto, muy schmittianamente, diciendo que la política analizada por Koselleck es una suerte de «guerra civil semántica». Guerra tanto más ardua y combatida cuanto que la pluralidad y variedad del espacio político de todos sus actores conlleva también una enorme riqueza de ideas y visiones. Pero, como ya viera Mill en su ensayo Use and Abuse of Political Terms: "La humanidad tiene muchas ideas, pero sólo unas pocas palabras» (Koselleck, 2006, 41): y donde hay escasez hay competencia y lucha. Posiblemente, no es así en otros ámbitos del lenguaje; por ejemplo, en el literario. Flaubert hacía casi una paráfrasis de Mill cuando decía, en el Préface à la vie d'écrivain, que «tenemos demasiadas cosas, y no suficientes formas»; pero lo que en la poesía significa el impulso hacia la creación de nombres y metáforas, la alegría creadora del artista, en política implica, mal que le pese a la simple alegría por lo multicultural o a las exhortaciones a multiplicar el vocabulario, una penuria de espacios para la aplicación conceptual: por eso, los significados están sobredeterminados y suelen ser multívocos. Lo que observa el historiador conceptual es que la política consiste en una lucha por hacerse con las palabras y ocupar los significados, o por no quedar excluidos de ellos, extendiéndolos o modificándolos. Así, por ejemplo: toda la historia de la lucha feminista podría ser vista como la lucha por introducir el género femenino en el significado de dignidad humana. Es esa lucha la que desgarra, transforma o modifica los conceptos, los resignifica e incluso crea conceptos nuevos: y sólo desde los con- 
ceptos, esos pocos conceptos compartidos por todos, se modela y modifica la realidad y la experiencia. Como en Kant, el concepto articula y posibilita la experiencia, en este caso histórica. Y al articularla, no sólo la recoge y condensa, sino que contribuye a transformarla; precisamente porque no se acopla con ella, porque los actores políticos, desde sus experiencias y expectativas, lo desacoplan. Saben que cada concepto «reúne en un haz la multiplicidad de la experiencia histórica y toda una suma de referencias objetivas teóricas y prácticas, estableciendo entre ellas una conexión que sólo por el concepto se da y sólo por el concepto se experimenta realmente» $(1978,109)$.

No es difícil ver ahora cómo esta «lucha por el significado», o la «guerra civil semántica», se encuentra con la «libertad de palabra para la discusión entre ciudadanos plurales» y dotados de la reflexividad del juicio que describe Arendt. La palabra que interviene en la política es un concepto limitado, y además de uso público, a disposición de todos. Como tal concepto, está cargado históricamente, arrastra toda una sedimentación histórica - más o menos transparente, más o menos reescribible, como toda historiaque define a su vez las posibilidades y responsabilidades de quien lo usa. El trabajo del concepto es, en efecto, un trabajo público, y como todo lo público, plural: un trabajo público de los conceptos. La libertad de palabra, que nace justamente de la apertura semántica de los conceptos políticos, y de las concepciones lingüísticas del mundo que tienen los agentes políticos, impulsa ese trabajo. La sedimentación histórica del significado, toda la carga de historia semántica del concepto, constituye, a su vez, la estofa que rellena el juicio a partir del cual actúa la espontaneidad de los actores. Éstos realizan juicios políticos e históricos - atribuyen significados globales a pro- cesos y fenómenos contingentes y singulares - a partir de cierta experiencia sedimentada. Lo que Koselleck enseña es que esa experiencia se ha sedimentado lingüísticamente, en conceptos dinámicos que la propia lucha política va transformando.

Puede ser que los partidarios de la llamada democracia deliberativa miraran con simpatía este esquema que estoy proponiendo. La lucha política se parecería a un diálogo platónico-hermenéutico donde los interlocutores se sumergen en una conversación a la búsqueda del concepto correcto y verdadero. Sin embargo, la perspectiva de Koselleck (y probablemente la de una Arendt más agonística) excluyen algo así. Pues el entramado de los conceptos se articula, como todas las estructuras lingüísticas, por pares de oposición que impiden una resolución última y unitaria. Por eso le da Koselleck tanta importancia a la constitución asimétrica de los conceptos y conceptos globales contrarios (1979, 211 ss.)

De esta propuesta de un «trabajo público de los conceptos» resultarían tres corolarios:

Primero, la llamada responsabilidad política es una responsabilidad conceptual. El historiador que, según Arendt, va implícito en cada actor, en cada ciudadano, y que es el que juzga, es un historiador conceptual. El ciudadano reflexivo que Kant-Arendt describen es un ciudadano consciente de la historia de los propios conceptos políticos, dispuesto también, por la presión de la discusión, a cierta revisión de su uso y significado. La capacidad de juicio presupone una competencia léxica. Ciertamente, toda reflexividad es limitada, como enseñaba Gadamer, el maestro de Koselleck; y no cabe pensar en algo así como una autotransparencia respecto al propio vocabulario conceptual. Ni el lenguaje ni la historia funcionan así. Pero la conciencia de 
esa responsabilidad por los conceptos, y de la limitación a su uso y conocimiento es precisamente una de las enseñanzas de los últimos dos siglos: si en algo coinciden Koselleck y Arendt al criticar la filosofía clásica de la historia, es que precisamente el uso irresponsable del concepto «historia» ha sido, es todavía, la coartada de las mayores fechorías.

Segundo, y con ello se responde a la pregunta inicial de este ensayo por el lugar del conocimiento y el aprendizaje histórico desde una perspectiva política. El recuerdo organizado que es la polis, la sabiduría histórica que resulta de la elaboración de las experiencias del pasado, se deposita en monumentos, en leyes, etc.; pero, sobre todo, en el lenguaje políticosocial cuyos conceptos se modulan en la lucha política. Tal vez esto signifique que los conceptos sociopolíticos, con todo su resquebrajamiento interno y con las tensiones de las luchas que encierran, pero también con toda la densidad de construcción histórica y de realización del presente que implican, son más que la «tumba insigne, distinta de aquélla en la que yacen» que, en verdad, la ciudad puede ofrecer a sus ciudadanos. Valga la sugerencia de este ejemplo final: la tarea de guardar la memoria de tragedias innombrales como el Holocausto, se realiza, tanto o más - tanto o más imperfectamente, como todo duelo, pero tanto o más piadosamente- que en monumentos más o menos impresionantes, conmovedores, commemoradores, tanto o más que allí, en los imprecisos y fracturados conceptos políticos a los que dio lugar, como el de genocidio, por ejemplo. Incluso arrojados a la arena política. Pero también de ahí, entonces, la responsabilidad por su uso.

Tercero, en una sociedad tan sobrecargada de pasado y de pretensiones de memoria y recuerdo histórico como está resultando ser la sociedad del final de la modernidad (o posmoderna, si quieren) esta comunidad de ciudadanos con conciencia histórico-conceptual no deja de tener un significado crítico. De hecho, muchas de las reivindicaciones de la llamada «memoria histórica» que se realizan hoy tienen lugar, bien por una aplicación acrítica de ciertos conceptos del presente al pasado; bien por la aceptación de que hay ciertos conceptos intemporales y eternos que unen a nuestros semejantes del pasado con nosotros (lo que vale tanto para muchos nacionalismos como para casi todos los abusos de la memoria). Frente a ello, una comprensión de la política como elaboración conceptual de las experiencias del pasado contribuiría a «drenar el presente» ${ }^{7}$ y a reactivar el papel de la conciencia histórica como parte de la actividad política, reconociendo, además, el papel propio del historiador en ella.

\section{BIBLIOGRAFÍA}

Arendt (1961): The Human Condition, Chicago.

- (1995): Was ist Politik, Piper.

- (1982): Lectures on Kant's Political Philosophy, Chicago.

Benjamin (1939): Über den Begriff der Geschichte, en Gesammelte Schriften, I, 2, Fráncfort, 1974, págs. 691-704.

- (1933): Erfahrung und Armut, en ib. págs. 213-219.

Koselleck (1959): Kritik und Krise, Fráncfort, Suhrkamp.

- (1979): Vergangene Zukunft, Fráncfort, Suhrkamp.

- (2006): Begriffsgechichten, Fráncfort, Suhrkamp. 


\section{NOTAS}

* Este trabajo se enmarca en el Proyecto de Investigación «Una nueva filosofía de la historia para una nueva Europa» (HUM2005-02006/FISO).

${ }^{1}$ Historia de la Guerra del Peloponeso, Madrid, Gredos, II, 43.

${ }^{2}$ La conmemoración, aunque inevitable en la vida pública, no es el modo más limpio de memoria. Todorov, Memoria del mal, tentación del bien, p. 159 ss.

3 Más agonística que colaborativa, por lo que se verá. Pero la indecisión persiste.

${ }^{4}$ Así, por ejemplo, el texto de Faustino Oncina, «Experiencia y política en la historia conceptual», Res publica, 1, p. 117.

5 Ello no implica, por supuesto, ningún paralelo entre las concepciones históricas de Koselleck y la filosofía de la historia teleológica que habitualmente se atribuye todavía a Hegel. Al margen de cómo se entienda la concepción hegeliana de la historia, se trata aquí de destacar que el concepto hegeliano, tal como él lo describe en la Fenomenología, trabaja y recoge la experiencia con esfuerzos y pautas muy parecidos a los de los conceptos sociopolíticos que estudia Koselleck; si bien éstos, como se sugerirá enseguida, caracterizan la negatividad de otra manera.

6 Phänomenologie des Geistes, Hamburgo, Felix Meiner, 1999, p. 126

7 La expresión es de Manuel Cruz, Las malas pasadas del pasado, Barcelona, Anagrama, 2005, p. 157. 